\title{
Hepatic artery pseudoaneursym formation follow- ing intraductal biliary radiofrequency ablation
}

A 73-year-old man with a history of liver transplantation developed cholestasis. No abnormality was seen on magnetic resonance imaging. Percutaneous cholangioscopy via a left-sided transhepatic tract ( Fig.1) demonstrated carpet-like villous change with biopsies showing highgrade dysplasia in the right and left ducts. Intraductal ultrasound (IDUS) showed a $\mathrm{T} 1$ lesion, with bile duct wall thickening to $2.4 \mathrm{~mm}$. Radiofrequency ablation (RFA) was performed in the right and left hepatic ducts with an 8-French catheter (Habib EndoHPB, EMcision, Montreal, Canada) at $10 \mathrm{~W}$ for 90 seconds. Sixteen days later the patient presented with melena, requiring transfusion of 6 units packed red blood cells. Angiography showed a $1.2-\mathrm{cm}$ pseudoaneurysm of the right hepatic artery, which was thrombosed with percutaneous thrombin injection. Subsequent cholangioscopy demonstrated successful ablation of the biliary dysplasia ( Fig. 1). The close temporal relationship of RFA to pseudoaneurysm formation, and the absence of other apparent etiologies, implicate intraductal RFA as the likely cause. RFA may be used to treat cholangiocarcinoma $[1,2]$ and intraductal extension of ampullary polyp [3]. The cross-sectional diameter of the RFA tissue ablation zone varies from 4.3 to $11.3 \mathrm{~mm}$ depending on the power and duration of treatment [4]. These values are probably underestimates, since they are based on ex-vivo experiments and do not take into account delayed tissue necrosis. We hypothesize that RFA induced necrosis of the bile duct wall and a portion of adjacent right hepatic artery, leading to pseudoaneurysm formation with subsequent rupture into the right hepatic duct.

The right hepatic artery may focally approach within $1 \mathrm{~mm}$ of the bile duct wall [5]. We now utilize IDUS immediately prior to RFA, and avoid performing RFA at $10 \mathrm{~W}$ wherever a vessel passes within $4 \mathrm{~mm}$ of the IDUS probe ( $\mathrm{Fig} .2$ ). However, when a closely approximating vessel cannot be avoided, we decrease the RFA energy setting.

Endoscopy_UCTN_Code_CCL_1AZ_2AI

Competing interests: None
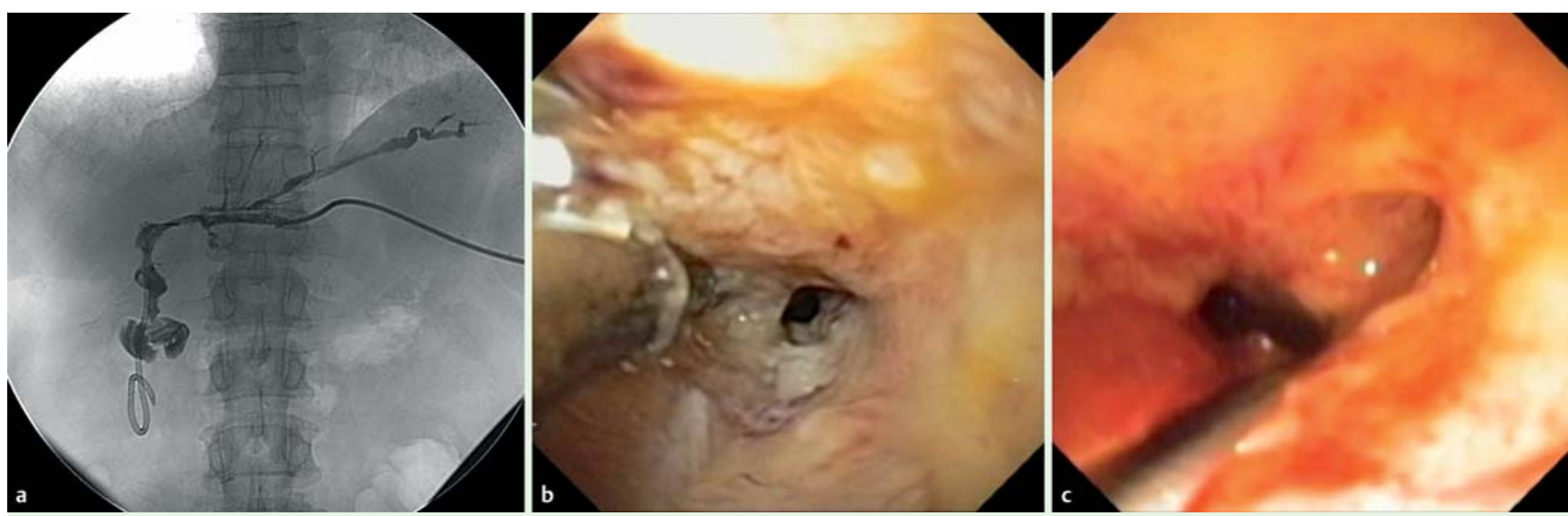

Fig. 1 Right hepatic duct dysplasia treated by intraductal biliary radiofrequency ablation: a cholangiogram before treatment shows poor filling of the right hepatic duct; $\mathbf{b}$ cholangioscopy of the right hepatic duct shows sessile polyp; $\mathbf{c}$ follow-up cholangioscopy of the right hepatic duct after treatment shows successful ablation of the polyp.
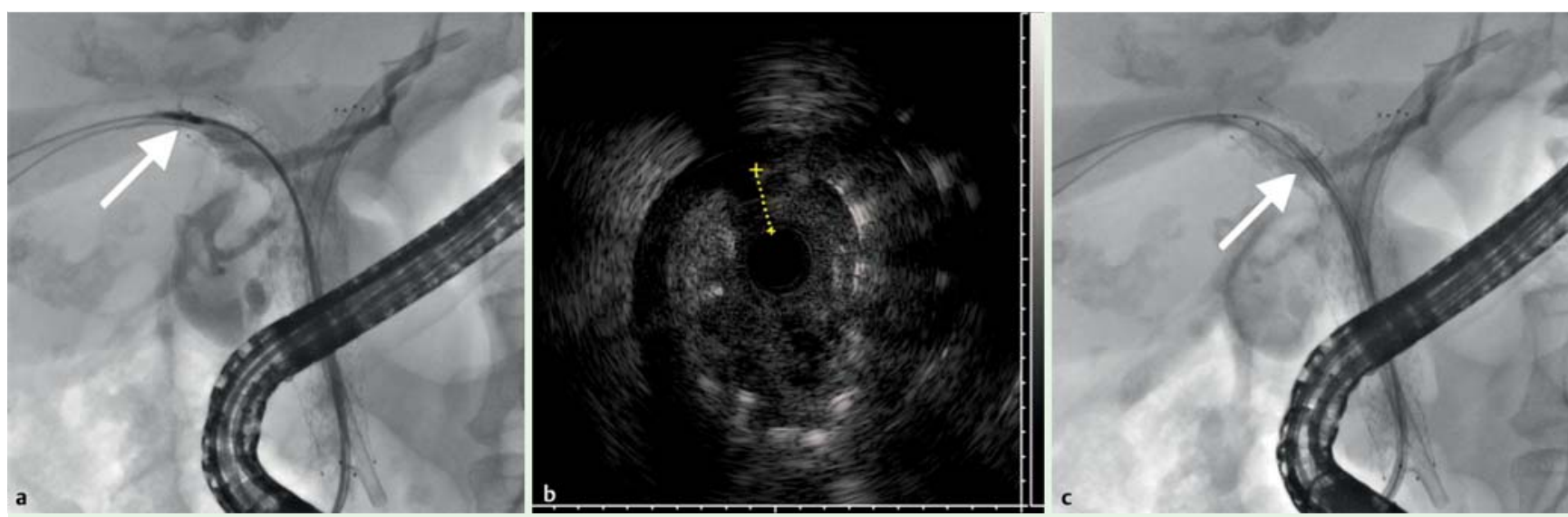

Fig.2 Intraductal ultrasound (IDUS) guides radiofrequency ablation (RFA) in a patient with hilar cholangiocarcinoma and recurrent stent occlusion: a IDUS probe (arrow) positioned at the proximal edge of a right hepatic biliary stent; $\mathbf{b}$ IDUS image at the same location shows the right hepatic artery approaching within $2.6 \mathrm{~mm}$ of the IDUS probe, with echogenic ends of the metal stent wires also visible; $\mathbf{c}$ RFA was performed within the stent (arrow), avoiding the location shown in $\mathbf{a}$ and $\mathbf{b}$. 


\section{Topazian', M. J. Levy'1, S. Patel²,} M. R. Charlton', T. H. Baron ${ }^{1}$

${ }^{1}$ Division of Gastroenterology and Hepatology, Department of Internal Medicine, Mayo Clinic, Rochester, Minnesota, USA

${ }^{2}$ Department of Radiology, Franciscan All Saint's Hospital, Racine, Wisconsin, USA

\section{References}

1 Monga A, Gupta R, Ramchandani M et al. Endoscopic radiofrequency ablation of cholangiocarcinoma: new palliative treatment modality (with videos). Gastrointest Endosc 2011; 74: 935-937

2 Steel AW, Postgate AJ, Khorsandi S et al. Endoscopically applied radiofrequency abla- tion appears to be safe in the treatment of malignant biliary obstruction. Gastrointest Endosc 2011; 73: 149-153

3 Dzeletovic I, Topazian MD, Baron TH. Endoscopic balloon dilation to facilitate treatment of intraductal extension of ampullary adenomas (with video). Gastrointest Endosc 2012; 76: $1266-1269$

4 Itoi T, Isayama H, Sofuni A et al. Evaluation of effects of a novel endoscopically applied radiofrequency ablation biliary catheter using an ex-vivo pig liver. J Hepatobiliary Pancreat Sci 2012; 19: 543-547

5 Tamada K, Ido K, Ueno $N$ et al. Assessment of the course and variations of the hepatic artery in bile duct cancer by intraductal ultrasonography. Gastrointest Endosc 1996; 44: $249-256$
Bibliography

Dol http://dx.doi.org/ 10.1055/s-0032-1326644 Endoscopy 2013; 45: E161-E162 (c) Georg Thieme Verlag KG Stuttgart · New York ISSN 0013-726X

Corresponding author M. Topazian, MD

Mayo Clinic 200 First St. SW

Rochester

MN 55905

USA

Fax: +1-507-266-3939

topazian.mark@mayo.edu 